\title{
UNDERGRADUATE PERCEPTION OF ONLINE EDUCATION IN JORDAN
}

\author{
Salem Alemaishat, Youngstown State University, salema@ysu.edu \\ Guy Philbin, Robert Morris University, philbin@rmu.edu
}

\begin{abstract}
This study measured perceptions of online education of full-time undergraduate students attending the universities of Jordan, Hashemite, Tafila Technical, and Al-Isra Private during a time of growing political, social, and military unrest in the Mashreg region, which includes Jordan, Lebanon, Palestine, Syria and Iraq. The feelings, beliefs, and attitudes of Jordanian students toward online education have never before been explored. As Mahmood, Hall, and Swanberg (2001) have pointed out, most online education research has focused on developed countries and very little research has been conducted in developing countries with emerging economies. Numerous scholars including Guessoum (2006) and Taha (2007) have concurred, pointing out that a paucity of research is particularly true with respect to online education in Middle Eastern countries such as Jordan. This exploratory study begins to fill the significant research gap that exists with respect to online education and technology in this emerging country.
\end{abstract}

Keywords: Undergraduate Perceptions, Online education, Jordan, Internet, Social Media, Mashreg

\section{INTRODUCTION}

The Internet has created a parallel universe where people conduct business, students learn online, and knowledge seekers access libraries electronically. This parallel universe has come to Jordan, but as yet is in its infancy. Jordan's universities - a bellwether of change in the Arab world that is strategically positioned between globalization and antiquity - are in the process of adopting this parallel universe. As the infrastructure supporting this technology grows, different segments of Jordanian society are participating in this new universe. The goal of this study was to provide preliminary data on the feelings, beliefs, and attitudes of undergraduates toward online education at four Jordanian institutions of higher learning. Jordan's Ministry of Higher Education and Scientific Research announced that Jordanian universities would begin offering fully online courses in 2010. More than six years on this has not happened. However, according to Malkawi (2015), Jordan's Higher Education Council recently announced that online bachelor's programs for undergraduates residing in Jordan as well as students outside the country will be made available, as well as allowing the Kingdom's universities to introduce blended learning programs. The Jordanian government has slowly made progress with respect to building infrastructure to support online education, developing systems to address information and communication technologies integration, as well as providing student and faculty training Guessoum (2006). Many Jordanian universities currently offer hybrid face-to-face and online courses, but the goal of offering totally online courses remains unfulfilled. This may soon change, as access to social technology is moving at an astounding rate. As the Pew Research Center (2014) recently reported in a survey of more than 24,000 people in 24 emerging and developing economies, Jordanians are neck-in-neck with China in cellphone and smartphone ownership. Approximately nine-in-ten people — or 95 percent of the populations of Jordan and China — now own mobile phones.

\section{LITERATURE OVERVIEW}

In a study comparing students' perceptions of distance and traditional learning, Hannay and Newvine (2006) reported that students preferred and "learned more" online than in a face-to-face environment. In addition to receiving higher grades online, the students indicated that they spent more time on their classes, found the text and instructional materials more useful, and perceived that distance classes were more difficult and of higher quality than traditional courses. Student views about online education varied greatly between those who had actually taken online courses as opposed to those who had never taken an online class: those with no online class familiarity believed the faculty would have low expectations; students who had taken at least one online course felt that high faculty expectations were common; and students' perceptions of high faculty expectations increased with their online course experience. Dobbs, Waid, and Del Carmen (2009) found that students perceived traditional face-to-face courses to be "easier" than online classes and that acceptance of online education increased as the number of online courses the 
students took increased. In a comparative analysis of learner satisfaction and learning outcomes in online and faceto-face learning environments, Johnson et. al. (2000) reported that in many respects online learning can be as effective as face-to face learning. In a study of online satisfaction, academic rigor and interaction, Wyatt (2003) also found that students felt that their online courses were more demanding than face-to-face courses. While students in the Wyatt study reported that online faculty expectations were higher than in traditional courses, they also felt overwhelmed at times, resulting in an increased dropout rate. Wyatt's investigation also indicated students' impressions that online education provided a high quality educational experience increased with age.

Parker (2003) found that most first-year students majoring in information technology and information systems perceived online education as more fun and of a higher quality than traditional venues. In addition, these first-year students believed that course information was easier to access and that this contributed to their academic success. Regarding student performance in online versus traditional classes, a study by Daymont and Blau (2008) found that undergraduate students performed equally well in both online and traditional settings. Howland and Moore (2002) found that students' expectations were a determining influence on their online course experience and strategies and reported that self-management, self-monitoring, and individual motivations were key factors for online success. On the downside, Picciano (2002) and Song, Singleton, Hill, and Koh (2004) found that lack of interaction, persistence, or both, can affect students' perceptions of how they feel about their performance in an online class. Summarizing briefly, a meta-analysis by Allen, Bourhis, Burrell and Mabry (2002) found that students had similar levels of satisfaction when it came to online and face-to-face classes.

While some previous studies including Yukselturk \& Bulut (2009), Astleitner \& Steinberg (2005), Arbaugh and Stelzer (2003), and Sierra \& Wang (2002) have suggested that gender effects were insignificant in online education, other research such as Chyung (2007) and Sullivan (2001) has suggested that male and female students have different perceptions of online education regarding performance, motivation, study habits, and communication behaviors. For example, Dabaj (2009) found that female students had more positive perceptions of online education than did male students. Price (2006) suggested that female students might be more independent and confident learners in the online environment than their male counterparts, while Rovai and Baker (2005) found that women tend to be task driven, detail oriented, organized, and manage their time better than do men - all important characteristics when pursing online education.

\section{SOCIO-CULTURAL FACTORS}

A growing body of evidence suggests that social and cultural differences and diversity among students should be considered in online courses, as these factors can enrich or detract from the learning experience. Richardson and Swan (2003) examined the effect of social factors on students' perception of online classes and their instructors. Their results showed a positive correlation between social factors and perceived learning and instructor quality. Moreover, the perception of success or performance in online learning classes varies by culture because cultural differences affect students' perceptions. For instance, Shattuck (2005) found that being culturally different from others can have a negative effect on students' contributions and participation in online courses. Shattuck's study showed that even in a highly interactive communication learning environment international students who took online classes felt marginalized and alienated from American students attending the same classes. Reeder, Macfadyen, Chase and Roche (2004) found that differences in cultural communication patterns resulted in an increase in the occurrence of miscommunications. English speaking students who obtained a Western education had the least difficulty in the online environment, while students from other cultures or different backgrounds without knowledge of English had a hard time communicating in the online environment. In another study by Fujuan, Nabb, Aagard, and Kioh (2010), attitudes toward online education were more positive among students who were proficient in English.

Online education offerings are increasing both nationally and internationally. We would hope that institutions want to understand how students from other cultures perceive online education and what effect those cultural differences might have on students taking online classes. Students in Western cultures, for example, are encouraged to interact with teachers and ask challenging questions. However, according to Zhang (2007), teachers in Eastern cultures hold total authority and students are hesitant to challenge, do not instruct in a reciprocal manner, and use examinations as the primary means of measuring performance. As might be expected, Zhao and McDougall (2008) found that students from Eastern cultures were not willing to enter into a conflict or challenge their instructors. To summarize, learning in Eastern cultures concentrates on memorization of materials presented by an infallible instructor; educa- 


\section{Issues in Information Systems \\ Volume 17, Issue I, pp. 37-46, 2016}

tion in the United States - especially online education - often involves and values regular interaction between peers and the instructor. These and other differences may place students from Eastern cultures at a disadvantage in online education.

\section{METHODOLOGY}

The data were collected in the Spring of 2011 at University of Jordan, the Hashemite University, Isra University, and Tafila Technical College resulting in a sample of convenience of 266 fully completed surveys. The instrument used for this study was a two-part paper survey with a total of 39 questions. Response categories were provided using a five-point Likert scale where $1=$ strongly disagree (SD) and $5=$ strongly agree (SA). The first part of the survey consisted of nine questions that gathered participant demographic information adapted from Tanner, Noser and Totaro (2009). This included gender, age, class rank, GPA, major, college, previous online education experience, type of experience, if any, and the student's country of origin. The second part consisted of 30 questions soliciting students' perceptions about technology, Internet usage, and online education. Twelve of these questions were also designed by Tanner, Noser and Totaro (2009); fifteen were designed by Mishra and Panda (2007); and we supplemented these empirically validated questions with three additional questions. The surveys data were entered into SPSS ${ }^{\circledR}$ for MAC 18.0. The results consisted of descriptive summaries of the participants' demographics, descriptive statistics of the students' perceptions of online education, descriptive statistics on personal characteristics, and statistical tests on the relationships between students' perceptions and personal characteristics.

\section{STUDENT PERCEPTIONS}

\section{Age}

The independent variable "Age" was divided into an 18-to-21-year-old group and a 21-years-or-older group to measure students' perceptions of online education. Previous studies by Wyatt (2003) indicated that when a student's age increased, the student's belief that online education provided high quality experience also grew. Wyatt's findings on age and perception of online education were supported by Tanner, Noser, Fuselier, and Totaro (2009), who suggested that students under 21-years-of-age were less in favor of online education. Consistent with previous studies, our results indicated that 21-year-old and older Jordanian students of both sexes had more positive attitudes toward online education than did 18-to-21-year-old students. Many older students prefer online education over traditional methods of instruction as it allowed them to obtain an education while being married and working. As in developed countries, an online environment allowed adult Jordanian students to meet both educational and family commitments.

\section{Competence}

The question of communication competence was collapsed to a "Yes" or No" answer and was used to measure the students' negative perceptions of online education. Students who indicated that they did not possess the communication competencies needed for online courses had significant differences in negative perception scores. The mean difference indicated that students who did not possess the necessary competencies had less favorable perceptions of online education than students who were competent. This suggests the possibility that students who did not report online competency were cautious or worried about online education because of unfamiliarity. Indeed, Hannay and Newvine (2006) found that students who had never taken an online course were not confident that they could do well in an online course.

A significant difference in negative perceptions of online education existed between students who reported they were incompetent using a computer and students who were not. The mean difference indicated that participants who were not computer literate had less favorable opinions of online education than did participants who were computer savvy. Individual computer incompetence associated with negative perceptions of online education is consistent with Challoo and Rodriguez's (2010) previous research that indicated lower technological skill sets led to lower perceptions of online education. It also resonated with the work of Miller and Pilcher (2000), which indicated that a technological skill set had a positive correlation with students' satisfaction of online education. 
Nevertheless, students who stated they had communications competence and students who did not both held similar positive perceptions of online education. Notably, this finding is inconsistent with the research of Challoo and Rodriguez (2010), which showed a positive correlation existed between student computer skills and their perceptions of online education. Our results suggest that although some students did not have the communication skills required for online courses, they were nevertheless open to the possibilities offered by distance learning technology. Moreover, as Al Doghmi et. al. (2013) have noted, increasing use of social media and web-based services among Arab youths in general and Jordanian university students in particular is building many of the skills required by online education.

\section{Internet Access}

Internet availability was surveyed to assess the impact of Internet access on students' perceptions of online education. Previous research by Mitra and Steffensmeier (2000) has suggested students with unlimited Internet access have a more favorable opinion of online education than those who did not. Our study indicated students who have access to the Internet would be more comfortable, less anxious, and have sufficient skills to participate in an online class than students without access. Our survey participants who had access to the Internet whenever they needed it had a more favorable opinion of online education than did participants who did not have ready access to the Internet.

This finding is in agreement with Challoo and Rodriguez (2010), as well as Mitra and Steffensmeier (2000), who suggest a computer-enriched environment, has a positive effect on students' opinion of online education. According to Central Intelligence Agency (2012) data, there were 69,473 Internet hosts (computers connected directly to the Internet) available within Jordan, which ranks 89th in the world in terms of Internet connectivity. This lack of Internet availability - be it for economic or logistical reasons - physically eliminates otherwise eligible students from accessing online classes. Access is also a significant issue in lower socioeconomic neighborhoods, which are abundant in developing countries, including Jordan. This is of particular concern for female students who would be less likely to seek Internet access in public places, as it is culturally unseemly for women to appear in such environments. Further, there is a significant cost to gaining Internet access in developing countries like Jordan, and in many cases, students have limited financial resources. Potential students who cannot afford access to the technology will most likely be lost.

\section{English}

Three questions concerning English proficiency were used to measure student perceptions of online education. Participants proficient in English had a more positive opinion of online education than students who were not proficient. This finding was in agreement with those reported by Fujuan, Nabb, Aagard (2010) who showed that students proficient in English perceived the online education environment more positively than other students. English proficiency is particularly relevant to this study because while the software used in online courses or the computers themselves are available to students in Arabic, there are many other tasks, error messages, and system-related functionalities that are still in English. This requires the students to have some knowledge of English to fully understand online course content and to effectively interact with the available online tools. Respondents who indicated that they used English with family and friends, or that English was required for their field of study, had more positive perceptions of online education than students who did not. This result was consistent with those reported by Reeder et. al. (2004), which showed that students who obtained a Western education, or were English speaking, had the least difficulty in the online environment.

Although instruction in Jordanian universities is primarily in Arabic, our results affirm the fact that English skills do in fact have a bearing on students' perceptions of online education. Overall, respondents who indicated that they were proficient in English scored lower in negative perception than those who indicated that they were not proficient in English. Our study further indicated that participants who were proficient in English had a more positive opinion of online education than participants who were not proficient in English. These results are consistent with previous research by Fujuan, Nabb, Aagard and Kioh (2010) that showed English proficiency has a positive correlation with students' perception of online education. Students not proficient in English possibly over estimated the English knowledge requirements needed for online education. Again, in Jordan this may also reflect the fact that classes are generally taught in Arabic; English instruction may push students beyond their comfort zones. Finally, as Lindsey (2015) has pointed out, teaching in English has divided the Arab world. English has become the language of instruction at several national universities, although, as the 2012 reversal of Qatar University's policy of English as the 


\section{Issues in Information Systems \\ Volume 17, Issue I, pp. 37-46, 2016}

"official teaching language" suggests, there is some understandable hesitancy on the part of the Arab speaking world to adopt English even when it is viewed more as a skill than a language.

\section{Gender}

Our results suggesting that female Jordanian students have more favorable attitudes toward online education may be traced to cultural and religious mores. Jordanians live in extended families where social segregation of the sexes is the norm. Men and women do not mix freely in public situations, which would include classrooms and public transportation. For Jordanian women, then, online education is more socially acceptable, as it offers more privacy than face-to-face environments and is in harmony with cultural mores. Further, a significant number of Jordanian students have limited financial resources and must use public transportation to travel to and from university. This is cumbersome for students - especially women - in terms of availability, cost of fare, and safety. By attending online classes, female Jordanian students enjoy more privacy and social comfort while avoiding a costly and difficult transportation system.

\section{Negative Perceptions}

An analysis of variance (ANOVA) was conducted to compare subjects from the University of Jordan, the Hashemite University, Isra University and Tafila Technical College on total scores for negative perceptions. This analysis was performed to test the assumption that students in private universities would score lower on the positive perception scores than students from public universities because the admission process in private universities is less stringent than admission to public universities. However, the results contradicted our assumption and indicated there was no significant difference of opinion of online education between Jordanian students from public and private universities. Moreover, the results of the mean difference of the analysis clearly showed that students of all ranks had similar negative perceptions of online education. As stated above, this finding was somewhat inconsistent with previous research indicating fourth-year students rated online education as being more useful than students in their first, second, or third years.

\section{Positive Perceptions}

An ANOVA between subjects from the University of Jordan, the Hashemite University, Isra University and Tafila Technical College was conducted to compare total scores for positive perceptions. This comparison was conducted to test the assumption that students in private universities would score lower on the positive perception score than students from public universities. Given the difference in the admission process for public and private universities, it seemed reasonable to assume private students would be less likely to have positive scores than their counterparts in public universities. While there was no statistically significant difference among most of the students at these universities, the perceptions of students at the University of Jordan were significantly different than students from Isra University. The mean difference indicated that students from the University of Jordan had more positive attitudes toward online education than students from Isra University.

Students from the only private university that participated - Isra University - obtained significance with the University of Jordan, where students scored higher in the positive perceptions test. A rank order analysis of the students' total scores for positive perceptions indicated that the perceptions of senior students were significantly different from freshman and sophomores (See Figure 1). Looking at the mean difference of the analysis clearly showed that senior students had a more positive attitude toward online education than did freshman or sophomores. This finding is consistent with previous research which indicated that fourth-year students rated online education as being more useful than students of lower ranks. An analysis of the students' GPAs revealed that there was no significant effect of the student's GPA on their positive perceptions of online education.

\section{LIMITATIONS}

This study had significant limitations. The number of participants surveyed was small compared with the total number of students enrolled at the universities represented. Thus the responses of this sample of convenience may not 
accurately reflect the attitudes of the total student populations. Further, this study relied on students' self-reporting of their communication competence to measure perceptions of online education - actual competence was not assessed. Future studies could provide more definitive and specific data and would benefit from a larger randomized sample.

\section{DISCUSSION}

Although the limitations listed above should be addressed in future studies, we feel the student perceptions of online education this study examined are worthy of consideration. In terms of higher education in the Middle East, perceptions of online education are vitally important. While a delivery method for education may not appear revolutionary at first blush, it should not be forgotten that education and universities are often the cradle of new ideas. The subsequent growth of these new ideas through a new delivery method may result in significant social, political, and economic changes. We believe that incorporating the social and religious mores of the region into the creation of an online learning environment could significantly increase its appeal and effectiveness. This study investigated only a few of the many possible relationships of students' perceptions of online education in Jordan. As Arbaugh (2005) has observed, long-term studies on factors predicting the success of Web-based courses are limited. Future research focused on students' perceptions regarding the design of online learning, the role of community, and social media and networking could provide additional knowledge of Jordanian students' perceptions and use of the online environment.

These findings will hopefully be beneficial to both students and universities in Jordan implementing online education in the future. As Rovai and Downey (2010) have observed, success or failure of distance education programs takes place in a global environment. By recognizing and acknowledging their students' perceptions, Jordanian institutions of higher learning will better understand how to enable success, for example, by offering prerequisite or remedial courses in basic English reading comprehension skills especially as they pertain to their online courses. Institutions could also more clearly define the technological skills needed for online course success, providing classes for students who need to upgrade their computer skills such as Internet usage, writing effective emails, use of discussion boards, downloading and uploading files. By addressing these areas early in the development of their online programs, universities in Jordan might better meet the needs of their students and create an atmosphere that would encourage and enable student success in this new environment.

It was very clear from the survey responses that there were significant differences in students' perceptions of online education. As might be expected, the differences were most noteworthy in the areas of language and computer literacy. Regarding language proficiency, the students proficient in English — whether they had a major that required English usage or they used English with their family and friends - had a more positive opinion of online education than students with inadequate English language skills. With respect to computer literacy, access to the Internet, the technology skills required for online classes, and computer competency all affected the students' opinions and expectations of online education. Those students with greater computer literacy had more favorable perceptions about online education than students with less computer literacy. Additional research examining possible links between computer literacy, faculty use of communications, the content and amount of online communication, and student perceptions could prove to be useful in implementing online courses in Jordan, especially where no online programs currently exist. Our overall results track well with those of Al-adwan and Smedley (2012), who concluded that cultural factors concerning student-instructor interaction and technical skills need to be addressed for Jordanian students to fully benefit from online learning opportunities.

\section{CONCLUSIONS}

Summarizing these points, understanding student perceptions is an important part of the development of effective online education programs. This is particularly so in Jordan and the Arab world in general where this type of learning is in its infancy and there is a paucity of research. Students' perceptions of online education in Jordan and elsewhere in the Middle East reflect the growth and power of social media and the turbulent ethos fostered by terrorism, war, and a growing refugee crisis. Cultural differences need to be more fully explored in order to understand and encourage better communication and participation by students of all backgrounds. Future studies of online education implementation might explore and include views of faculty, institutional views of online education, and institutional 


\section{Issues in Information Systems}

Volume 17, Issue I, pp. 37-46, 2016

plans as they affect students' perceptions. The digital revolution has not yet fully come to the Middle East. We hope Jordan will be ready to take advantage of the economic power online education offers when the moment is at hand.

\section{REFERENCES}

Al-adwan, A. \& Smedley, J. (2012). Implementing e-learning in the Jordanian higher education system: Factors affecting impact. International Journal of Education and Development using Information and Communication Technology, 8(1),121-135.

Al Doghmi, A., Al-Shalabi, H., Odeh, J., Andraws, Ss., Awajan, A. \& Alrabea, A. (2013). The academic use of social networks among university students in Jordan. International Journal of Computer Science Issues. 10(5), 134-141.

Allen, M., Bourhis, J., Burrell, N., \& Mabry, E. (2002). Comparing student satisfaction with distance education to traditional classrooms in higher education: A meta-analysis. The American Journal of Distance Education. $16(2), 83-97$.

Arbaugh, J. (2005). Is there an optimal design for online MBA courses? Academy of Management Learning \& Education. 4, 135-149.

Arbaugh, J.B. \& Stelzer, L. (2003). Learning and teaching via the web: What do we know? In C. Wankel \& R. DeFillippi (eds.) Educating Managers with Tomorrow's Technologies (pp. 17-51). Greenwich, CT: Information Age Publishing.

Astleitner, H., \& Steinberg, R. (2005). Are there gender differences in web-based learning? An integrated model and related effect sizes. Association for the Advancement of Computing Education Journal. 13(1), 47-63.

Central Intelligence Agency. (2012). The World Factbook. Retrieved from: https:/www.cia.gov/library/publications/the-world-factbook/geos/jo.html

Challoo, L., \& Rodriguez, R. (2010). Student perceptions on distance education programs using course management systems. Journal of Technology Integration in the Classroom. 2(2), 144-152.

Chyung, S. Y. (2007). Age and gender differences in online behavior, self-efficacy and academic performance. Quarterly Review of Distance Education. 8(3), 213-222.

Dabaj, F. (2009). The role of gender and age on students' perceptions towards online education. Turkish Online Journal of Educational Technology. 8(2).

Daymont, T., \& Blau, G. (2008), Student performance in online and traditional sections of an undergraduate management course. Journal of Behavioral and Applied Management. 9(3), 275-294.

Dobbs, R., Waid, C., \& Del Carmen, A. (2009). Students' perceptions of online courses: The effect of online course experience. The Quarterly Review of Distance Education. 10(1), 9-26.

Fujuan, T., Nabb, L., Aagard, S., \& Kim, K. (2010). International ESL graduate student perceptions of online learning in the context of second language acquisition and culturally responsive facilitation. Adult Learning. 21(1/2), 9-14.

Guessoum, N. (2006). Online learning in the Arab world. Elearn Magazine. Retrieved from http://www.elearnmag.org/subpage.cfm?section=articles\&article $=40-1$ 
Hannay, M., \& Newvine, T. (2006), Perceptions of distance learning: A comparison of online and traditional learning. MERLOT Journal of Online Learning and Teaching, 2(1) 1-11. Retrieved from http://jolt.merlot.org/documents/MS05011.pdf

Howland, J., \& Moore, J. (2002). Student perceptions as distance learners in internet-based courses. Distance Education. 23(2), 183-195.

Johnson, S., Aragon, S., Shaik, N., \& Palma-Rivas, N. (2000). Comparative analysis of learner satisfaction and learning outcomes in online and face-to-face learning environments. Journal of Interactive Learning Research. 11(1), 29-49.

Lindsey, U. (2015, June 12). How teaching English divides the Arab world. The Chronicle of Higher Education. A14.

Mahmood, M. A., Hall, L., \& Swanberg, D. L. (2001). Factors affecting information technology usage: A metaanalysis of the empirical literature. Journal of Organizational Computing and Electronic Commerce. 11(2), $107-130$.

Malkawi, K. (2015, April 21). Jordan Times. Retreived from http://www.jordantimes.com/news/local/universitiesbe-allowed-offer-online-ba-degrees.

Miller, G., \& Pilcher, C.L. (2000). Are off-campus courses as academically rigorous as on campus courses? Journal of Agricultural Education. 41(2), 65-72.

Mitra, A., \& Steffensmeier, T. (2000). Changes in student attitudes and student computer use in a computer-enriched environment. Journal of Research on Technology in Education. 32 (3), 417-433.

Parker, M. (2003), Technology-enhanced e-learning: Perceptions of first year information systems students at the Cape Technikon. Proceedings of the South African Institute of Computer Scientists and Information Technologists. SAICSIT 2003, 316-319.

Pew Research Center. (February, 2014). “Report: Emerging Nations Embrace Internet, Mobile Technology: Cell phones nearly ubiquitous in Many Countries. " Retrieved from:

http://www.pewglobal.org/2014/02/13/emerging-nations-embrace-internet-mobile-technology

Picciano, A. (2002). Beyond student perceptions: Issues of interaction, presence, and performance in an online course. Journal of Asynchronous Learning Networks. 6(1), 21-40.

Price, L. (2006). Gender differences and similarities in online courses: challenging stereotypical views of women. Journal of Computer Assisted Learning. 22(5), 349-359. doi:10.1111/j.1365-2729.2006.00181.x

Reeder K., Macfadyen L. P., Chase M., \& Roche J. (2004). Falling through the (cultural) gaps? intercultural communication challenges in cyberspace. The University of British Columbia Digital Repository. Retrieved from: https://circle.ubc.ca/bitstream/handle/2429/1329/ReederCatac.pdf?sequence=1

Richardson, J., \& Swan, K. (2003), Examining social presence in online courses in relation to students' perceived learning and satisfaction. Journal of Asynchronous Learning Networks, 7(1), 68-88.

Rovai, A., \& Baker, J. (2005). Gender differences in online learning: Sense of community, perceived learning, and interpersonal interactions. The Quarterly Review of Distance Education. 6 (1), 31-44.

Rovai, A., \& Downey, J. (2010). Why some distance education programs fail while others succeed in a global environment. Internet \& Higher Education, 13(3), 141-147. doi:10.1016/j.iheduc.2009.07.001. 


\section{Issues in Information Systems}

Volume 17, Issue I, pp. 37-46, 2016

Shattuck, Kay (2005). Glimpses of the global Coral Gardens: Insights of international adult learners on the interactions of cultures in online distance education. Doctoral dissertation. The Pennsylvania State University, USA. Retrieved from Dissertations \& Theses: A\&I (Publication No. AAT 3193240).

Sierra, C., \& Wang, M. (2002). Gender, discourse style, and equal participation in online learning. In G. Richards (Ed.) Proceedings of E-Learn 2002 Conference (pp. 2364-2367), Chesapeake, VA: AACE.

Song, L., Singleton, E., Hill, J., \& Koh, M. (2004), Improving Online Learning: Student Perceptions and Challenging Characteristics. Internet and Higher Education. 7, 59-70.

Sullivan, P. (2001). Gender differences and the online classroom: male and female college students evaluate their experiences. Community College Journal of Research and Practice. 25, 805-818.

Taha, A. (2007). Networked e-information services to support the e-learning process at UAE University. The Electronic Library. 25(3), 349-362.

Tanner, J. R., Noser, T. C., \& Totaro, M. W. (2009). Business faculty and undergraduate students' perceptions of online learning: A comparative study. Journal of Information Systems Education. 20(1), 29-40. Retrieved from http://www.editlib.org/p/105718

Wyatt, G. (2003). Satisfaction, academic rigor and interaction: perceptions of online instruction. Education. 125(3), 460-468.

Yukselturk, E., \& Bulut, S. (2009). Gender differences in self-regulated online learning Environment. Educational Technology \& Society. 12(3), 12-22.

Zhang, J. (2007). A cultural look at information and communication technologies in Eastern education. Education Technology Research and Development. 55(3), 301-314.

Zhao, N., \& McDougall, D. (2008). Cultural influences on Chinese students' asynchronous online learning in a Canadian university. The Journal of Distance Education. 22(2), 59-80. 
APPENDIX

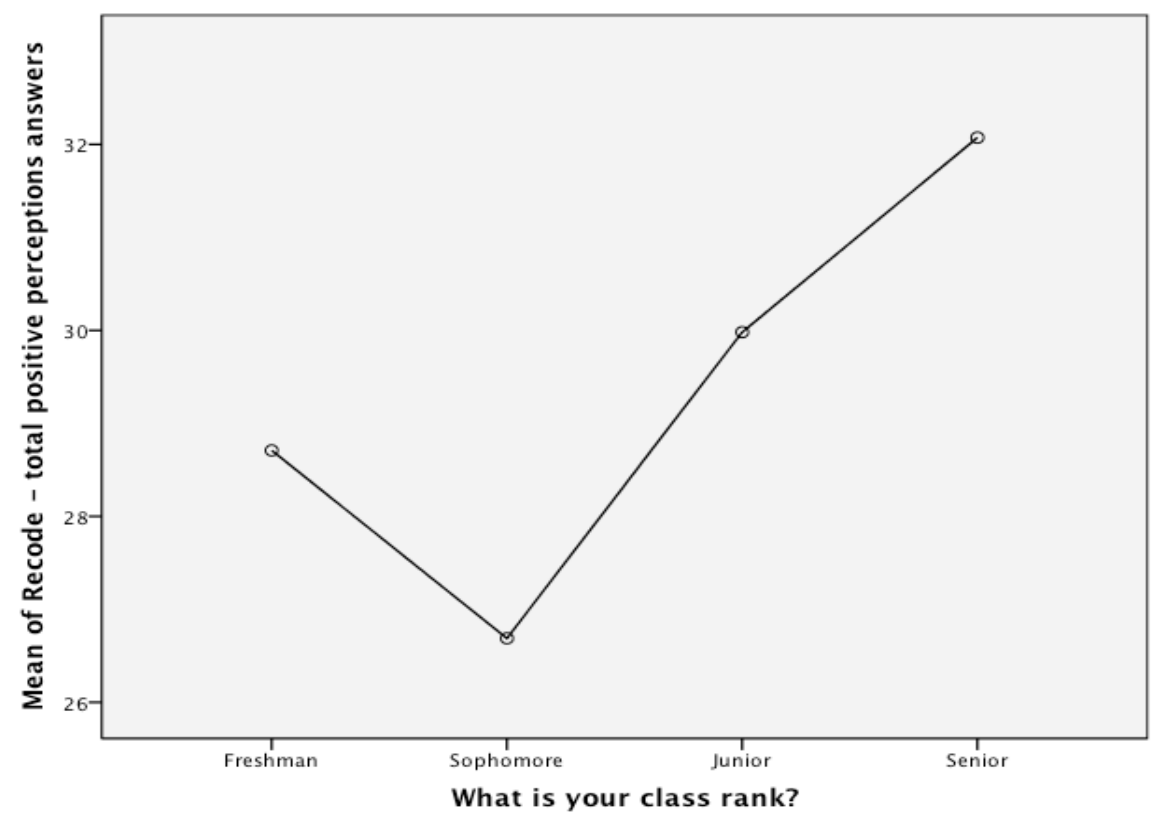

Figure 1. Students' Class Rank and Corresponding Positive Perceptions Responses

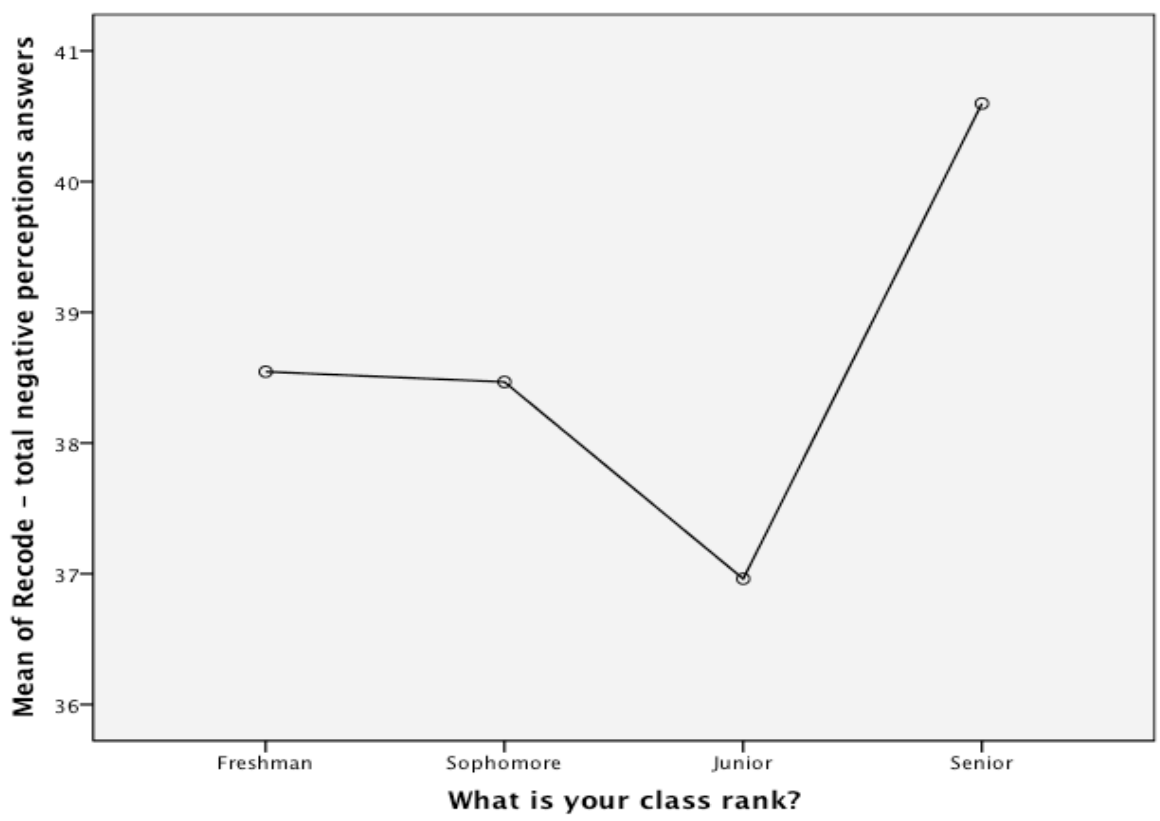

Figure 2. Students' Class Rank and Corresponding Negative Perceptions Responses 